\title{
Clinical Profile and Outcome of Aluminum Phosphide-Induced Esophageal Strictures
}

\author{
Rakesh Kochhar • Usha Dutta • Kuchhangi Sureshchandra Poornachandra • \\ Kim Vaiphei $\cdot$ Suraj Bhagat $\cdot$ Birinder Nagi $\cdot$ Kartar Singh
}

Published online: 21 April 2010

(C) American College of Medical Toxicology 2010

\begin{abstract}
Aluminum phosphide (AlP) is a lethal solid fumigant pesticide which has been recently linked to esophageal stricture formation. This paper aims to study the clinical profile and response to treatment of AlPinduced esophageal strictures. Data on all patients of AlPinduced strictures seen between January 2004 and June 2008 were retrieved and analyzed for clinical parameters and response to endoscopic dilation. Each patient underwent barium swallow to define the site and length of stricture and then was dilated endoscopically. Twelve patients of AlP-induced esophageal stricture (seven males) with a mean age of $26.83 \pm 8.43$ years were evaluated. They had consumed one to three AlP tablets, 4-156 weeks before reporting to us. They had onset of dysphagia within 2 to 8 weeks of ingestion of AlP. Of 14 strictures in 12 patients, seven were in upper third, two in middle third, and five in lower third of esophagus with a mean length of $1.96 \pm$ $0.75 \mathrm{~cm}$. Nine patients responded to dilation requiring $5.56 \pm$ 2.65 dilations. Four patients were given intralesional steroids to augment the effect of dilation. Three patients failed and were operated upon. All patients remained symptom free over

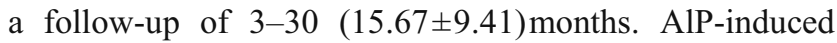

Presented at 7th meeting of Asia-Pacific Association of Medical Toxicology at Chandigarh, India, December 8-10, 2008

R. Kochhar $(\bowtie) \cdot$ U. Dutta $\cdot$ K. S. Poornachandra $\cdot$ S. Bhagat

B. Nagi $\cdot$ K. Singh

Department of Gastroenterology,

Postgraduate Institute of Medical Education and Research,

Chandigarh 160012, India

e-mail: dr_kochhar@hotmail.com

K. Vaiphei

Department of Pathology,

Postgraduate Institute of Medical Education and Research,

Chandigarh 160012, India esophageal strictures can be dilated endoscopically in a majority of patients; however, $25 \%$ of them require surgical intervention. AlP-induced esophageal strictures, thus, behave like caustic-induced strictures.

Keywords Aluminum phosphide $\cdot$ Esophageal $\cdot$ Strictures

\section{Introduction}

Aluminum phosphide (AlP) is a commonly used fumigant pesticide. It is used across India by farmers [1]. Even in the USA it is used extensively for protecting grains. When it comes in contact with moisture, it releases phosphine gas in an exothermic reaction $(\mathrm{AlP}+3 \mathrm{H} 2 \mathrm{O} \rightarrow \mathrm{Al}(\mathrm{OH}) 3+\mathrm{PH} 3+$ heat energy) [2]. Systemic toxicity results from absorption of phosphine gas and subsequent inhibition of respiratory chain enzymes and liberation of free oxygen radicals [3, 4]. Toxicity can result from inhalation of phosphine or absorption of phosphine from gut mucosa if AlP is ingested. Survivors are not known to have any specific sequelae [5]. Recently, however, ingestion of AlP has been reported to lead to esophageal strictures which behave like caustic-induced strictures [6-12]. We here report our experience with AlP-induced esophageal strictures in the last 5 years.

\section{Material and Methods}

The clinical details of all patients diagnosed to have AlPinduced esophageal strictures between January 2003 and June 2008 were retrieved and analyzed. Data recorded included the number of tablets consumed, circumstances leading to ingestion, immediate symptoms and duration, 
and degree of dysphagia at the time of presentation. Each patient was subjected to a barium contrast study to delineate the number and site of esophageal stricture(s). Endoscopy was performed subsequently to confirm the findings at radiology. Dilation of strictures was started using SavaryGilliard (SG; Wilson Cook, Winston Salem, VA, USA) dilators or through-the-scope balloons (Boston Scientific Inc. Watertown, MA, USA), depending upon the tightness of the strictures. Subsequent dilations were carried out at 3-weekly interval using SG dilators. The endpoint of dilation was $15 \mathrm{~mm}$. At each sitting, not more than three dilators were passed. Those who failed to open up in four sessions were subjected to intralesional triancinolone acetonide injection ( $40 \mathrm{mg}$ in four quadrants) as described earlier [13]. Those who still failed to respond were subjected to transhiatal esophagectomy and colon interposition. All patients were followed-up till September, 2008 (Fig. 1).

\section{Results}

A total of 12 patients (seven males/five females) with mean $( \pm \mathrm{SD})$ age of $26.83 \pm 8.43$ years (range $16-46$ years) with
AlP-induced esophageal stricture were seen by us (Fig. 2). All of them had ingested AlP tablets with suicidal intent. Seven of the 12 patients gave history of ingesting tablets previously exposed to air for a variable period. One of them said that she had taken out a tablet from a gunny bag full of wheat grains and ingested it. All the patients had ingested the tablet(s) with $50-100 \mathrm{ml}$ of water. The interval between ingestion of AlP and onset of dysphagia was 4 to 8 weeks (mean 5.92 \pm 1.68 ). They presented to us at a median delay of 9 weeks (range 4-156 weeks) following ingestion. Two patients had two strictures while ten patients had a single stricture (Figs. 3 and 4). Of the 14 strictures, seven were in upper third of esophagus, two in middle third of esophagus, and five in lower third. The length of the stricture was $1-$ $3 \mathrm{~cm}$ (mean $1.96 \pm 0.75 \mathrm{~cm}$; Table 1 ).

Three of the 12 patients had reported to a nearby hospital with vomiting after ingesting ALP tablets and were subjected to gastric lavage and supportive care. Another patient developed shock and acute renal failure following ingestion of three tablets of AlP and was hospitalized for 3 weeks in a local hospital. He had confluent ulceration at the stricture site when he came to us, 5 weeks later. Only one other patient had esophageal ulceration when he

Fig. 1 Treatment algorithm in AlP-induced esophageal strictures

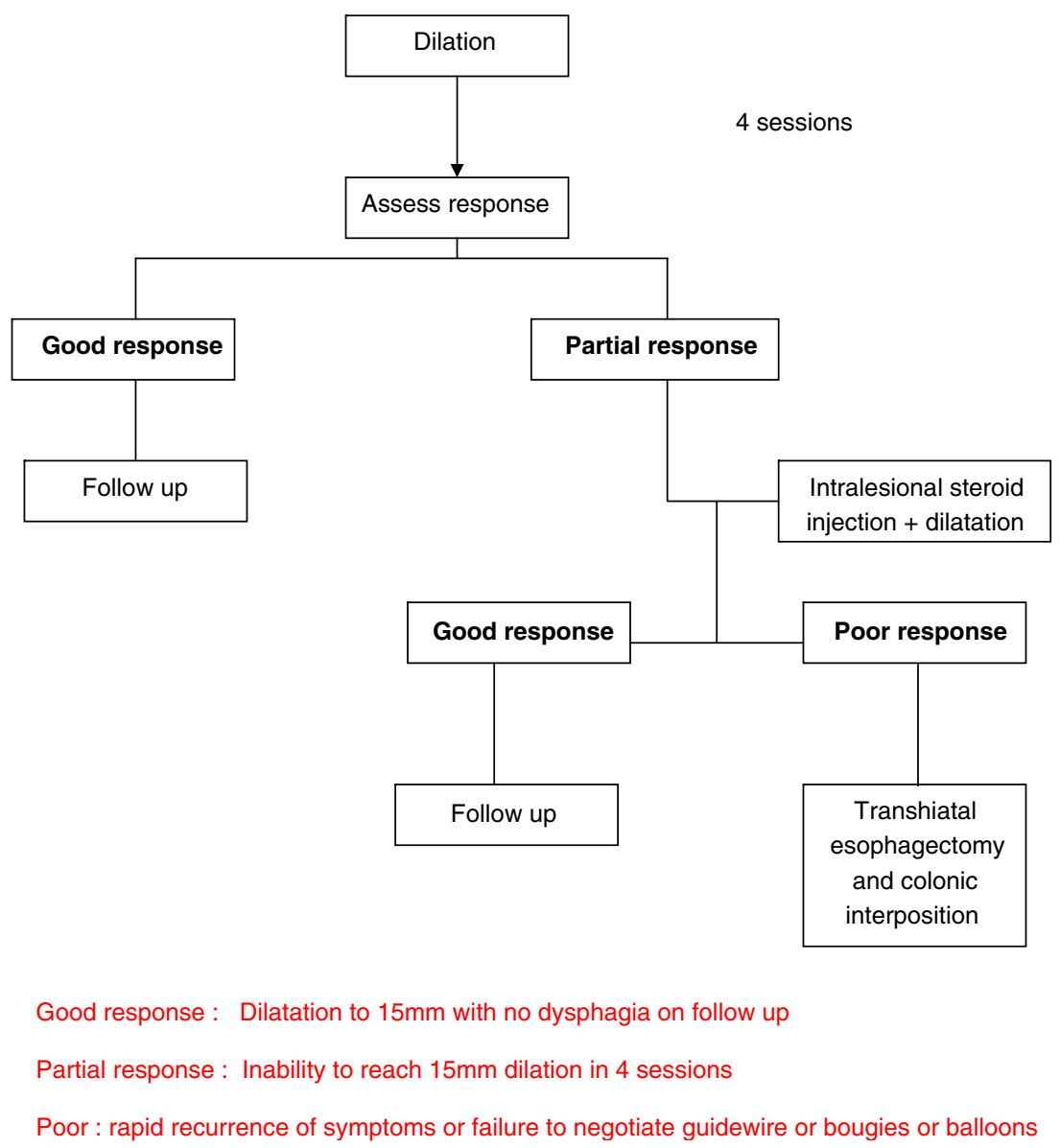


Fig. 2 Results of the treatment

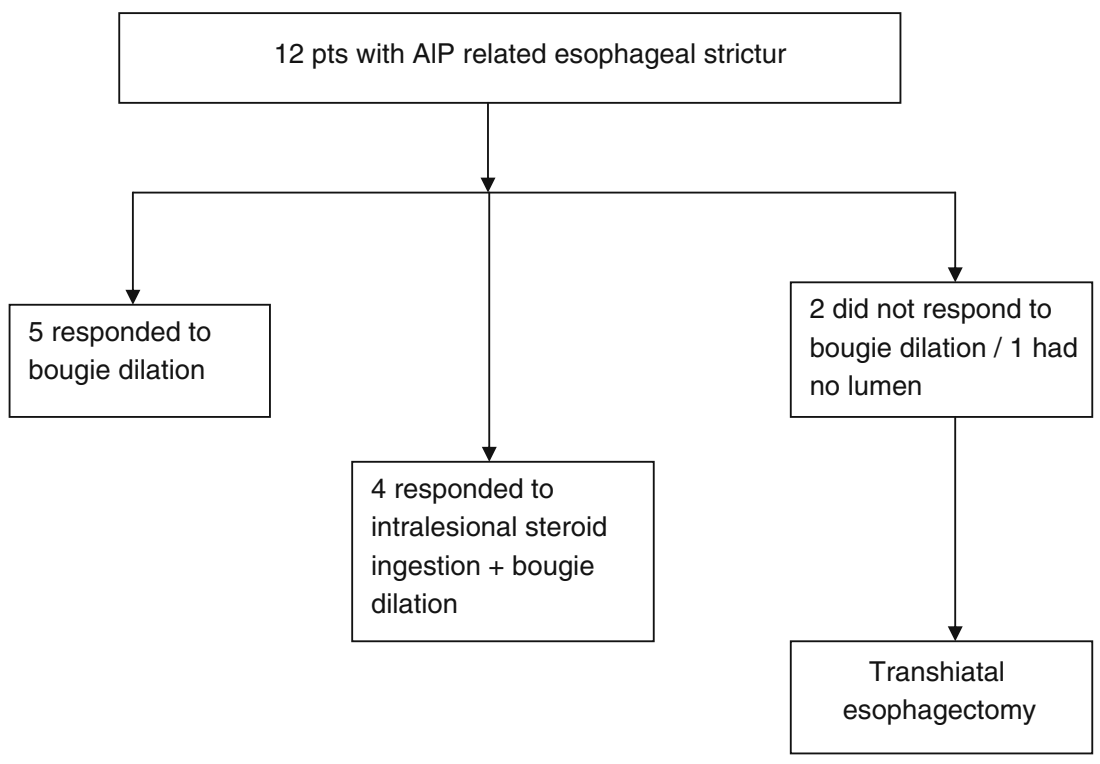

reported to us. All others had smooth esophageal strictures with complete epitheliazation. Two patients had undergone six and eight sessions of endoscopic dilation before coming to us and one patient had been subjected to jejunostomy feeding. All 12 patients were taken up for dilation. Nine $(75 \%)$ patients were successfully dilated to $15 \mathrm{~mm}$ in $5.42 \pm$ 2.54 (range 2-9) sessions. These nine patients gained a median of $2 \mathrm{~kg}$ weight (range 1-7 kg) following successful dilation. In those who had a successful outcome the mean number of dilations was $5.56 \pm 2.65$ (range 2-9). Intralesional steroids were used in four patients, with a mean of $2.3 \pm 1.3$ sessions (range $1-5$ ).

Fig. 3 Barium swallow showing a single AlP-induced strictures in mid-third esophagus
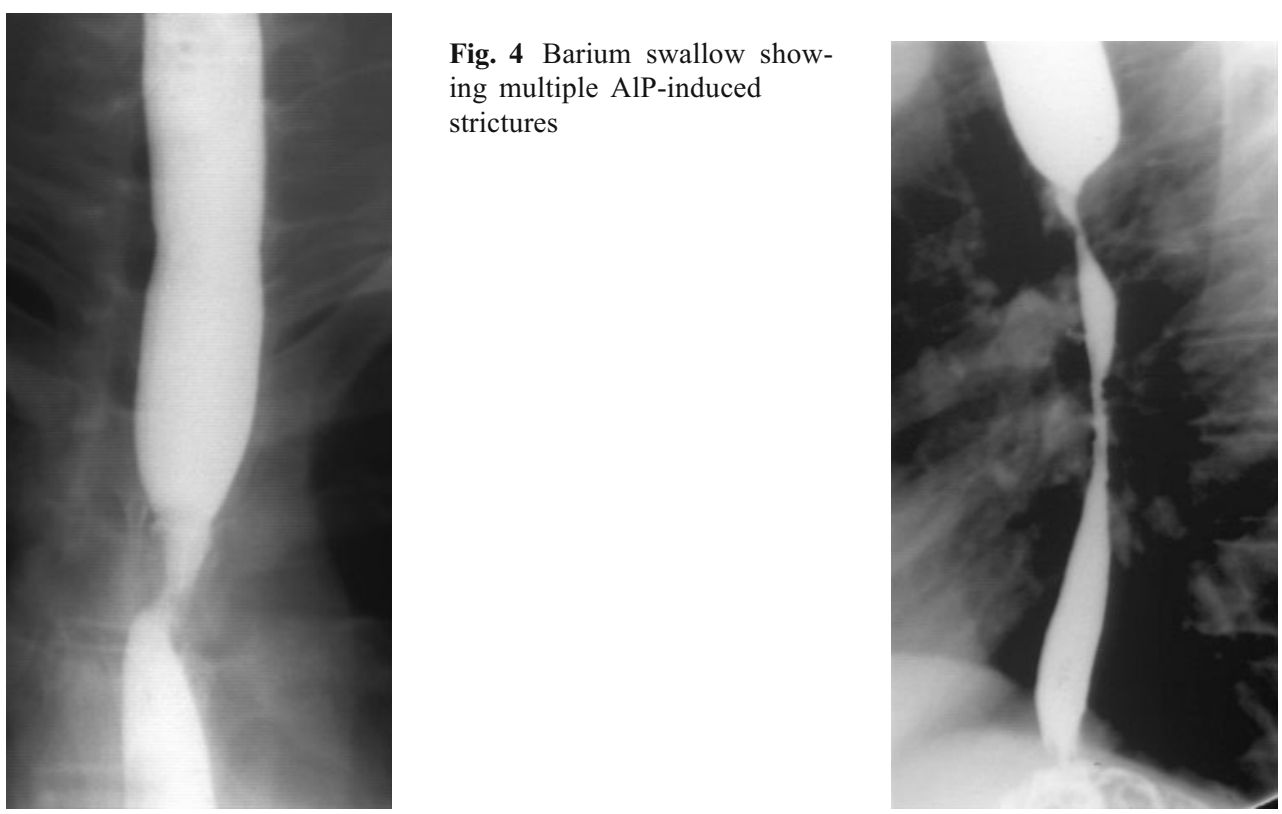

Fig. 4 Barium swallow showing multiple AlP-induced

strictures

Three patients failed to respond to dilation and were subjected to transhiatal esophagectomy and colon interposition. One of them had total occlusion of esophageal lumen through which even a guidewire could not be passed. In two patients esophageal lumen could not be maintained despite dilation to 10 and $12 \mathrm{~mm}$ and two sessions of intralesional steroids (Fig. 2). The stricture length in these and two patients was 2.0 and $3.0 \mathrm{~cm}$. The stricture number and site did not influence efficacy or failure of dilation. All the 12 patients have remained well over a follow-up of $3-$ $30(15.67 \pm 9.41)$ months. Histology of the resected specimen in one of the patients who underwent esophagectomy 
Table 1 Characteristics of patients with outcome

\begin{tabular}{|c|c|c|c|c|c|c|c|c|c|c|}
\hline $\begin{array}{l}\text { Age } \\
\text { (years) }\end{array}$ & Sex & $\begin{array}{l}\text { No. AlP } \\
\text { tablets }\end{array}$ & $\begin{array}{l}\text { Time lag to } \\
\text { development of } \\
\text { symptoms (weeks) }\end{array}$ & $\begin{array}{l}\text { Time lag to start } \\
\text { of dilation } \\
\text { (weeks) }\end{array}$ & $\begin{array}{l}\text { No. of } \\
\text { stricture(s) }\end{array}$ & $\begin{array}{l}\text { No. of } \\
\text { dilatations } \\
\text { to } 15 \mathrm{~mm}\end{array}$ & $\begin{array}{l}\text { Weight } \\
\text { gain (kg) }\end{array}$ & $\begin{array}{l}\text { Use of } \\
\text { intralesional } \\
\text { steroids }\end{array}$ & $\begin{array}{l}\text { Follow-up } \\
\text { (months) }\end{array}$ & Outcome \\
\hline 19 & $\mathrm{~F}$ & 2 & 4 & 4 & 2 & 8 & 6 & - & 14 & Success \\
\hline 30 & M & 1 & 6 & 20 & 1 & 6 & 2 & + & 12 & Success \\
\hline 23 & M & 2 & 4 & 20 & 2 & 2 & 2 & - & 26 & Success \\
\hline 33 & M & 3 & 4 & 5 & 1 & 8 & 7 & + & 25 & Success \\
\hline 32 & M & 1 & 8 & 16 & 1 & 3 & 1 & + & 11 & Success \\
\hline 23 & M & 1 & 7 & 156 & 1 & 2 & 1 & - & 12 & Success \\
\hline 46 & $\mathrm{~F}$ & 1 & 4 & 8 & 1 & 4 & 1 & - & 16 & Surgery $^{a}$ \\
\hline 17 & $\mathrm{~F}$ & 1 & 8 & 20 & 1 & 6 & 6 & + & 27 & Success \\
\hline 27 & M & 1 & 5 & 4 & 1 & 6 & 2 & - & 28 & Success \\
\hline 16 & F & 2 & 4 & 8 & 2 & 9 & 4 & - & 30 & Success \\
\hline 32 & F & 1 & 6 & 8 & 1 & 3 & 3 & - & 11 & Surgery $^{a}$ \\
\hline 24 & M & 1 & 8 & 8 & 1 & 4 & 2 & - & 14 & Surgery $^{\mathrm{a}}$ \\
\hline
\end{tabular}

AlP aluminum phosphide

${ }^{\text {a }}$ Transhiatal esophagectomy and colon interposition

showed mild to moderate chronic inflammatory cell infiltration in the subepithelium (Fig. 5)

\section{Discussion}

Aluminum phosphide has gained notoriety as a fatal pesticide when consumed by humans. The principal cause of death is cardiac arrhythmias, shock, acidosis, and adult respiratory syndrome due to absorption of phosphine gas [14]. Each 3-g tablet of AlP produces $1 \mathrm{~g}$ of toxic

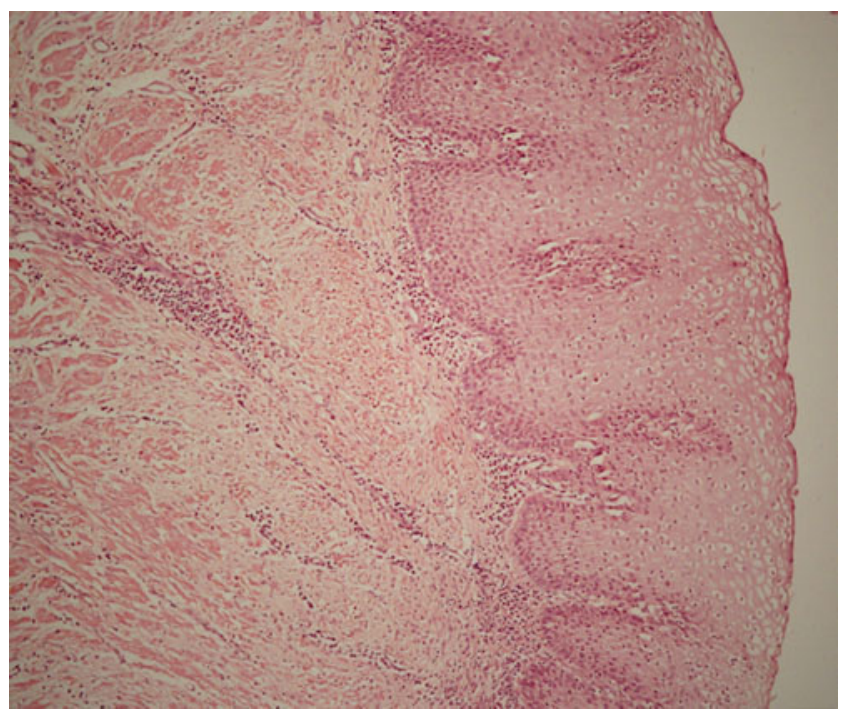

Fig. 5 Photomicrograph of the resected esophagus in a patient who underwent transhiatal esophagectomy showing intact mucosa with mild to moderate chronic inflammatory cell infiltration in the subepithelium $(\mathrm{H} \& \mathrm{E}, \times 240)$ phosphine gas when it comes in contact with moisture [14]. The average time interval between poisoning and death is $3 \mathrm{~h}$ with a range of $1-48 \mathrm{~h}$. As many as $95 \%$ of fatalities occur within first $24 \mathrm{~h}$ [15]. Most individuals consuming AlP with suicidal intent swallow the tablets/ pellets with water or dissolve them in water before swallowing. Accidental poisoning has been reported in freight carriers carrying wheat grain [16]. The lethal dose of AlP is as low as $1.5 \mathrm{~g}$ [17]. The overall mortality is high, though mortality is highly variable depending on various factors like freshness of the tablets, duration and severity of poisoning, and severity of shock and its response to resuscitative measures [18].

While gastrointestinal symptoms are common after AlP ingestion, esophageal stricture formation is reported only rarely [6-12]. There are only a total of 37 cases reported in the literature. Detailed inquiry into our patients revealed that seven of the 12 patients had consumed previously exposed tablets, perhaps diminishing the toxicity. As the tablet is quite large (18-20 $\mathrm{mm}$ in diameter), it can get lodged in esophagus at sites of physiological narrowing especially if consumed with a small amount of water. The anticholine-esterase property of phosphine gas also retards esophageal transit and increases the contact time [19]. Once lodged in the esophagus, it would release phosphine gas locally in an exothermic reaction. The other product of the chemical reaction is $\mathrm{Al}(\mathrm{OH})_{3}$ which is alkaline and is used as an antacid. The esophageal injury is presumably the result of thermal injury and stricture formation is a consequence of esophageal ulceration akin to pillesophagitis [20]. Caustic injury to the esophagus due to clinetest tablets [21] or battery ingestion [22] has similar 
pathogenesis and presentation with localized injury and stricture formation.

Two of our patients had ulceration in the stricture segment with local extravasation of the contrast; one who came to us after 5 months of ingestion and the other who came 2.5 months later. The local mechanism of injury is further evident by the fact that those with two strictures had consumed two tablets and no mucosal changes were noticed beyond the esophagus. Deeper ulceration could erode into the respiratory tree. There are two cases of AlPinduced tracheo-esophageal fistula, reported in the literature both having active ulceration which presumably eroded into the trachea [8].

There is only one brief report on occurrence of erosive gastroduodenitis in four patients of AlP ingestion who underwent endoscopy after hemodynamic stabilization [23]. There are no data in the literature on pathological changes in patients with AlP-induced esophageal stricture. The autopsy data in the literature on patients dying of AlP ingestion include congestion in gastrointestinal tract, heart, liver, and other organs [17]. It would appear that patients who develop esophageal stricture differ from those who have systemic toxicity in terms of degradation of the tablet because of prior exposure to air/moisture. There could also be differential absorption of phosphine gas from the squamous epithelium of esophagus, as compared to the columnar epithelium of the stomach. In any case esophageal ulceration and stricture formation would occur only if the tablet gets lodged in the esophagus. We have histopathological findings in one of our patients who underwent transhiatal esophagectomy and it showed intact mucosa with mild to moderate chronic inflammatory cell infiltration in the subepithelium.

AlP-induced strictures behave like corrosive-induced strictures. All the reported cases in the literature as well as our patients had short $(1-3 \mathrm{~cm})$ strictures. In the study by Misra and Dwivedi, all 15 patients had a single stricture [6]. However, two of our 12 patients had two strictures. One of these patients had consumed a single tablet of AlP while the other one had ingested two tablets. Three of our 12 patients failed to respond to endoscopic dilatation. One of these patients had near complete occlusion of esophageal lumen which precluded placement of spring-tipped steel guide wire. Attempts to dilate with balloon dilators were also unsuccessful and he was subjected to surgery. Two patients failed to maintain adequate esophageal lumen despite repeated dilation, including injection of triamcinolone acetonide. The number of dilations required for successful dilation in nine patients who responded was 2 to 9 (mean \pm SD, 5.56 \pm 2.65 ). In the study by Misra and Dwivedi, an average of three dilations was required in their patients. They had used endoscopic needle-knife incision to augment the results in two of their patients [6]. We used intralesional steroids in four of our patients in accordance with our previous experience of using this technique in difficult strictures [13]. Intralesional triamcinolone acetonide injections prevent collagen laying and recurrence of fibrosis once dilation is carried out [13]. This form of therapy is less expensive as compared to stent placement and safer as compared to needle-knife incision.

In another recent report Darbari et al. resorted to surgery in four of their 11 patients, in three because of poor response to bougienage and in one because of tracheoesophageal fistula [8]. There is also a report of resistant stricture due to AlP who required insertion of a plastic stent [7]. These reports $[7,8]$ and our experience suggest that AlP-induced strictures are often difficult to treat and may require additional procedures like endoscopic incision, intralesional steroids, or use of stents.

This report thus highlights the clinical profile of AlPinduced esophageal strictures. Strictures probably result from local injury and are usually caused by exposed tablets. The fact that they can be associated with deep ulceration and esophago-respiratory fistula reflects the depth of esophageal injury. The large size of the tablet and the anticholinergic action of phosphine gas may be primarily responsible for the stricture development. Though the strictures are short, they can be difficult to dilate and may need additional measures like intralesional steroid injection. We suggest that survivors of AlP poisoning should be investigated for mucosal injury and its consequences by radiological and/or endoscopic examination.

\section{References}

1. Chugh SN, Kishore K, Aggarawal N et al (2000) Aluminium phosphide is a widely used fumigant pesticide. Assoc Physicians India 48:855-856

2. Tripathi SK, Gautam CS, Sharma PL (1992) Clinical pharmacology of aluminiumphosphide poisoning. Ind J Pharmacol 24:134 137

3. Chefurka W, Kashi KP, Bond EJ (1976) The effect of phosphine [gas toxic to insects] on electron transport in mitochondria. Pestic Biochem Physiol 6:65-84

4. Bolter CJ, Chefurka W (1990) Extramitochondrial release of hydrogen peroxide from insect and mouse liver mitochondria using the respiratory inhibitors phosphine, myxothiazol, and antimycin and spectral analysis of inhibited cytochromes. Arch Biochem Biophys 278:65-72

5. Dave HH, Dave TH, Rakholia VG, Kharod PN, Jaju HJ (1994) Delayed hemorrhagic stroke following accidental aluminium phosphide ingestion. J Assoc Phys India 42:78-79

6. Misra SP, Dwivedi M (2009) Aluminum phosphide-induced esophageal strictures: a new cause of benign esophageal strictures. J Clin Gastroenterol 43:405-409

7. Somani SK (2008) Aluminium phosphide-induced esophageal stricture palliation with polyflex stent. Dysphagia 23:411-412

8. Darbari A, Tandon S, Chaudhary S, Bharadwaj M, Kumar A, Singh GP (2008) Esophageal injuries due to aluminum phosphide 
tablet poisoning in India. Asian Cardiovasc Thorac Ann 16:298300

9. Nijhawan S, Rastogi M, Tandon M, Mathur A, Rai RR (2006) Aluminum phosphide induced esophageal stricture: an unusual complication. Endoscopy 38(Suppl 2):E23

10. Talukdar R, Singal DK, Tandon RK (2006) Aluminium phosphide-induced esophageal stricture. Indian $\mathrm{J}$ Gastroenterol 25:98-99

11. Kapoor S, Naik S, Kumar R, Sharma S, Pruthi HS, Varshney S (2005) Benign esophageal stricture following aluminium phosphide poisoning. Indian J Gastroenterol 24:261-262

12. Madan K, Chalamalasetty SB, Sharma M, Makharia G (2006) Corrosive-like strictures caused by ingestion of aluminium phosphide. Natl Med J India 19:313-314

13. Kochhar R, Makharia GK (2002) Usefulness of intralesional triamcinolone in treatment of benign esophageal strictures. Gastrointest Endosc 56:829-834

14. Siwach SB (2003) Emerging epidemic of aluminium phosphide poisoning in northern India. In: Das S (ed) Medicine update. Shovan, Bhubaneshwar, pp 917-921

15. Ranga GS, Dwivedi S, Agarwal M, Kumar D (2004) Aluminium phosphide poisoning in a young adult: a suicidal cardiotoxin simulating myocardial ischaemia. JIACM 5:369
16. Wilson R, Lovejoy FH, Jaeger RJ, Landrigan PL (1980) Acute phosphine poisoning aboard a grain freighter. Epidemiologic, clinical, and pathological findings. JAMA 244:148-150

17. Siwach SB, Yadav DR, Arora B, Dalal S (1988) Acute aluminium phosphide poisoning: an epidemiological, clinical, and histopathological study. J Assoc Phys India 36:594-596

18. Chugh SN, Chugh K, Ram S, Malhotra KC (1991) Electrocardiographic abnormalities in aluminium phosphide poisoning with special reference to its incidence, pathogenesis, mortality and histopathology. J Ind Med Assoc 89:32-35

19. Mittra S, Peshin SS, Lall SB (2001) Cholinesterase inhibition by aluminium phosphide poisoning in rats and effects of atropine and pralidoxime chloride. Acta Pharmacol Sin 22:37-39

20. Abid S, Mumtaz K, Jafri W, Hamid S, Abbas Z, Shah HA, Khan AH (2005) Pill-induced esophageal injury: endoscopic features and clinical outcome. Endoscopy 37:740-744

21. Burrington JD (1975) Clintest burns of the esophagus. Ann Thorac Sur 20:400-404

22. Yardeni D, Yardeni H, Coran AG, Golladay ES (2004) Severe esophageal damage due to button battery ingestion: can it be prevented. Pediatr Surg Int 20:496-501

23. Chinna RS, Thukral R, Chawla LS (1992) Aluminium phosphideinduced gastroduodenitis. Gastrointest Endosc 38:635-636 (letter) 